\title{
The Implications of Higher TGF- $\beta 1$, IGF-II and IGF-1R mRNA Expression in Infiltrating Breast Carcinoma and Their Association with Tumorigenesis and Angiogenesis
}

\author{
Sachin Gupta ${ }^{1,2}$, Kusum Joshi ${ }^{3,}$ J. D. Wig ${ }^{4}$ and Sunil K. Arora ${ }^{2, *}$ \\ ${ }^{1}$ Department of Microbiology and Immunology, University of Miami, Miller School of Medicine, Miami, Florida- \\ 33136, USA. \\ ${ }^{2}$ Department of Immunopathology, ${ }^{3}$ Histopathology and ${ }^{4}$ General Surgery, Postgraduate Institute of Medical Education \\ \& Research, Chandigarh, India
}

*Corresponding Author

Sunil K. Arora, Ph.D., MNAMS

Additional Professor

Department of Immunopathology

Postgraduate Institute of Medical Education \& Research,

Chandigarh-160012, India

Ph.: 0091-172-2755192, FAX: 0091-172-2744401

Email: skarora_in@yahoo.com

Received: 12 January 2009; | Revised: 18 February 2009; | Accepted: 1 March 2009

\begin{abstract}
Insulin-like growth factor (IGF) and transforming growth factor (TGF) systems are implicated in breast tumorigenesis and are known to facilitate angiogenesis. The aim of the present study was to analyze intratumoral expression of various growth factors i.e TGF- $\beta 1$, IGF-II, IGF-1R and to determine, whether their expression correlated with angiogenesis and other clinicopathological factors in infiltrating breast carcinoma in North Indian patients. Intratumoral expression of TGF- $\beta 1$, IGF-II and IGF-1R genes was analyzed by RT-PCR in 60 biopsies of infiltrating breast carcinoma and compared that with its levels in their adjacent normal tissue. A comparative analysis of expression of each factor was done along with their relationship with angiogenesis in terms of intratumoral expression of vascular endothelial growth factor (VEGF, an invasogenic and angiogenic growth factor) and intratumoral microvessel density (IMD, a prognostic marker for angiogenesis). The relative mRNA abundance of all these genes was found to be higher in tumor tissues as compared to normal tissues. Statistical analysis of data revealed significantly higher values of TGF- $\beta 1$ transcripts in tumor tissues $(\mathrm{p}<0.001)$ as compared to normal tissues, that relate positively with the expression of angiogenic factors like VEGF and IMD in the tumor microenvironment. Further a significant correlation between expression of IGF-1R and higher grade tumors $(\mathrm{p}<0.05)$ was observed. A linear association of intratumoral TGF- $\beta 1$ expression with invasion and vascularity suggests/indicates a role of TGF- $\beta 1$ in the pathogenesis of tumor angiogenesis.
\end{abstract}


Keywords: IGF-II; IGF-1R; TGF- $\beta 1$; VEGF; intratumoral microvessel density (IMD); infiltrating breast carcinoma.

\section{Introduction}

Normal growth and differentiation of the mammary gland depends on the action of endocrine hormones concert with locally produced growth factors such as members of transforming growth factor $\beta$ (TGF- $\beta$ ) family and insulin-like growth factors (IGFs). TGF- $\beta 1$ has also been reported to both inhibit [1] as well as stimulate [2] proliferation of breast cancer cells. It acts as a multifunctional regulatory protein, contributing to cell differentiation, cell migration, extracellular matrix formation, angiogenesis, and immune functions [3-4].

Multiple lines of evidence support the role of IGFs, acting through the IGF-1 receptor (IGF-1R), in normal mammary growth and morphogenesis as well as in mammary tumorigenesis [5-6]. IGFs are potent mitogens in numerous cancer cell lines and are modulated by estrogens [7]. Binding of IGF-II to the IGF-1R activates intrinsic tyrosine kinase activity, and, triggers several signal transduction pathways, resulting in increased proliferation and reduced apoptosis [8]. The expression of IGF-1R, which is found in high concentrations in primary breast cancers, is crucial for tumor cell proliferation.

Another vital component in the development, progression and metastasis of many human tumors is angiogenesis. Vascular endothelial growth factor (VEGF), also known as vascular permeability factor (VPF) is a multifunctional cytokine that stimulates angiogenesis by increasing vascular permeability and by acting as an endothelial-cell mitogen [9]. At present, the most widely used method to quantitate tumor angiogenesis in human solid tumors is the count of Intratumoral microvessel density (IMD) [10]. A high density of microvessels in the stroma of breast tumors correlates with an increased likelihood of lymph node or distant metastasis [11].

TGF $\beta 1$ has been shown to induce angiogenesis in vitro [12] as well as in vivo [13] and is found to have angiogenic effect in breast cancer [13-14]. TGF- $\beta 1$ acts as an indirect angiogenic agent as it regulates VEGF expression by breast carcinoma cells [15]. Lee et al [16] provided the evidence that IGF-II directly promotes angiogenesis by stimulating the migration and morphological differentiation of endothelial cells, and suggested that this factor may play a role in the progression of the cancer by promoting the deleterious neovascularization. Kucab and Dunn [17] considered the potential role of IGF-1R in regulating breast cancer metastases by facilitating angiogenesis and lymphangiogenesis through the induction of VEGF.

The aim of the present study was to study the expression of growth factors like TGF- $\beta 1$, IGF-II and IGF-1R in infiltrating breast carcinoma in North Indian patients to determine the relationship of these growth factors with tumor progression. The work entailed the analysis of the expression of these growth factors and correlate with levels of angiogenic factors like VEGF and IMD and certain clinicopathological parameters such as age, menopausal status, chemotherapy status, tumor stage, histologic tumor grade, lymph node metastasis.

\section{Materials and methods}

\section{Acquisition of Samples}

Sixty patients undergoing mastectomy were included in the study after informed consent. Breast carcinoma tissue samples were obtained from the surgical O.T. of the Nehru Hospital attached with Post Graduate Institute of Medical Education and Research, Chandigarh, India. Tissue samples from the breast biopsies were frozen in OCT compound and a diagnosis was made on a haematoxylin and eosin $(\mathrm{H} \& \mathrm{E})$ stained frozen section. The diagnosis was subsequently confirmed on permanent sections.

For the purpose of gene expression study, a portion of the tissue was stored at $-70^{\circ} \mathrm{C}$ and processed for reverse transcription-polymerase 
chain reaction (RT-PCR) analysis and the other was processed for routine histopathological analysis. For each tissue sample studied, clinicopathological data including age, tumor stage, histological type of tumor, histological grade and axillary lymph node metastasis status was recorded. Tumor Staging was done according to most widely accepted clinical staging system for breast carcinoma, adopted by both International Union against Cancer (UICC) and the American Joint Commission on Cancer staging. It was based on TNM system [18]. Tumor grade was assessed on routine $\mathrm{H} \& \mathrm{E}$ stained slides using method described by Elston and Ellis [19].

\section{Semi-quantitative gene expression of IGF-II,} IGF-1R, TGF- $\beta 1$ and VEGF

The relative abundance of mRNA of each of these growth factor genes was semi-quantitatively estimated in each tissue by reverse-transcriptase PCR (RT-PCR) as described previously (15). Briefly total cellular RNA was isolated from the tumor tissue and their corresponding normal tissue using GITC method [20]. For RT-PCR, the complementary DNA strands (cDNA) were made from $2 \mu \mathrm{g}$ of total RNA from each tissue using MMLV reverse transcriptase enzyme (MBI fermentas, Lithuania) and random hexamers. For each PCR reaction, cDNA template was mixed to a standard reaction mixture consisting of $1 \mathrm{X}$ reaction buffer, $1.5 \mathrm{mM} \mathrm{MgCl}_{2}, 200 \mu \mathrm{M}$ of each dNTPs, 0.5 pmoles of each oligonucleotide primer and 1.5 units of Taq DNA polymerase (Roche, Germany). Amplification of $\beta$-actin gene was used for normalization during quantitation as well as an internal quality control. The sequence of the primers [4, 21-23], annealing temperatures and their product sizes are stated below as:

Sequence of primers and their annealing temperatures

\begin{tabular}{|l|c|c|}
\hline \multicolumn{1}{|c|}{ Primers Sequence } & $\begin{array}{c}\text { Annealing } \\
\text { temperature }\end{array}$ & $\begin{array}{c}\text { PCR Product } \\
\text { size }\end{array}$ \\
\hline $\begin{array}{l}\text { TGF- } \beta \text { 1 sense- 5'-GCC CTG GAC ACC AAC TAT TGC T-3' } \\
\text { TGF- } \beta \text { ' antisense- 5'-AGG CTC CAA ATG TAG GGG CAG G-3' }\end{array}$ & $64^{\circ} \mathrm{C}$ & $161 \mathrm{bp}$ \\
\hline IGF II sense- 5'-TCC TGG AGA CGT ACT GTG CT-3' & $58^{\circ} \mathrm{C}$ & $258 \mathrm{bp}$ \\
IGF II antisense- 5'-CTT GGG TGG GTA GAG CAA TC-3' & & \\
\hline IGF-1R sense- 5'-AGG ACG GCT ACC TTT ACC CGG CAC AAT TAC-3' & $68.5^{\circ} \mathrm{C}$ & $883 \mathrm{bp}$ \\
IGF-1R antisense- 5'-ATC AAC AGG ACA GCG ACG GGC AGA-3' & & \\
\hline VEGF sense: 5'-GAG GAG GGC AGA ATC ATC AC-3' & $58^{\circ} \mathrm{C}$ & $341 \mathrm{bp}$ \\
VEGF antisense: 5'-AGG CCA CAG GGA TTT TCT TGT C-3' & & \\
\hline
\end{tabular}

Quantitation of TGF- $\beta 1$, IGF-II, IGF-1R, and VEGF gene expression was done by comparing the signal intensities of RT-PCR product of these genes to those of $\beta$-actin gene from the same RNA sample using agarose gel electrophoresis containing ethidium bromide. The quantitative expression of each gene is given as the percent of constitutively expressed $\beta$-actin gene for each tissue sample.

\section{Immunohistochemistry for IMD}

For microvessel density, the tissue sections were stained for endothelial cells using an antiCD34 monoclonal antibody signifying neovascularization. Tissue sections (5 $\mu$ thick) were taken on poly-L-lysine coated slides. After deparaffinization and rehydration, the sections Am. J. Biomed Sci. 2009, 1(2), 157-165; doi: 10.5099/aj090200157 were subjected to microwave treatment in $0.01 \mathrm{M}$ citrate buffer $(\mathrm{pH}$ 6.0) for 15 min., for antigen retrieval. The sections were stained overnight at $4^{\circ} \mathrm{C}$ with $10^{-1}$ dilution of CD34 antibody (Dako, Denmark). A biotinylated anti-mouse antibody followed by streptavidin horseradish peroxidase was used sequentially for $30 \mathrm{~min}$ before color developement using chromogenic diamino benzidine (DAB $0.5 \mathrm{mg} / \mathrm{ml}$ ) in the presence of $0.1 \% \mathrm{H}_{2} \mathrm{O}_{2}$. Sections were then counterstained with haematoxylin. Sections of primary breast carcinomas in which primary antibody was omitted served as negative controls. Individual microvessels were counted in the area of highest vascularity. Any brown stained endothelial cell or cluster that was separate from other nearby microvessels was counted [24].

(c) 2009 by NWPII. All rights reserved. 


\section{Statistical Analysis}

For each group and subgroup of patients, TGF$\beta 1$, IGF-II, IGF-!R, and VEGF mRNA expression as $\%$ of $\beta$-actin mRNA values (Mean and SEM) were calculated. Among infiltrating carcinoma, the comparison of intratumoral gene expression and microvessel density with clinicopathological variables was done with unpaired student's t-test. Where indicated, a one-way analysis of variance (ANOVA) was performed. Correlation analysis was performed using Pearson's correlation coefficient. All statistical analyses were carried out with the use of SPSS software for windows 10.0. Tests were considered as significant when their $\mathrm{p}$ values were $<0.05$.

Table 1. Clinicopathological characteristics of the patients

\begin{tabular}{|c|c|}
\hline & Number of Patients \\
\hline \multicolumn{2}{|l|}{ Breast } \\
\hline Left & 29 \\
\hline Right & 31 \\
\hline \multicolumn{2}{|l|}{ Menopausal Status } \\
\hline Premenopausal & 26 \\
\hline Postmenopausal & 34 \\
\hline \multicolumn{2}{|l|}{ Age } \\
\hline Age $\leq 48$ & 33 \\
\hline Age $>48$ & 27 \\
\hline \multicolumn{2}{|l|}{ Chemotherapy } \\
\hline Yes & 40 \\
\hline No & 20 \\
\hline \multicolumn{2}{|l|}{ Histological type } \\
\hline Infiltrating ductal carcinoma & 56 \\
\hline Infiltrating lobular carcinoma & 2 \\
\hline Apocrine carcinoma & 1 \\
\hline Papillary carcinoma & 1 \\
\hline \multicolumn{2}{|l|}{ Tumor Stage } \\
\hline Stage IIA & 15 \\
\hline Stage IIB & 31 \\
\hline Stage IIIA & 11 \\
\hline Stage IIIB & 3 \\
\hline \multicolumn{2}{|l|}{ Tumor Grade } \\
\hline IDC 1 & 8 \\
\hline IDC 2 & 37 \\
\hline IDC 3 & 11 \\
\hline \multicolumn{2}{|l|}{ Lymph node metastasis } \\
\hline Negative & 31 \\
\hline Positive & 29 \\
\hline
\end{tabular}

\section{Results}

\section{Clinicopathological characteristics}

The study was carried out on 60 samples of infiltrating breast carcinoma along with equal number of their adjacent normal tissue. Forty patients $(66.67 \%)$ were on neo-adjuvant chemotherapy, out of which 36 patients received post-operated adjuvant therapy. Twenty six $(43.33 \%)$ of the patients were premenopausal and the rest 34 (56.67\%) were postmenopausal. Only one patient gave family history of breast carcinoma. Table 1 shows the clinicopathological characterstics of the patients like age, tumor stage, histological type of tumor, histological grade and axillary lymph node metastasis status.

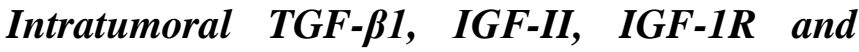 VEGF mRNA Expression and Clinicopathological Findings}

The Intratumoral mRNA expression of TGF$\beta 1$, IGF-II, IGF-1R and VEGF genes were analyzed by RT-PCR in normal and tumor tissue samples (Figure 1A). The relative mRNA abundance of all these genes was found to be higher in tumor tissues as compared to normal tissues. Significantly higher levels of intratumoral TGF- $\beta 1$ expression were found in infiltrating carcinoma samples as compared to normal tissue samples $(\mathrm{p}=0.0004$, Figure 1B). Intratumoral VEGF mRNA expression was significantly higher in infiltrating tumor as compared to normal tissue $(\mathrm{p}<0.0001$, Figure 1B). Table 2 shows the correlation between various growth factors and various clinicopathological parameters. Analysis of variance by one way ANOVA revealed no significant difference except in IGF-1R levels ( $p=0.0483$ ), which were significantly higher in high grade tumors. There was inverse relationship of TGF- $\beta 1$ gene expression with lymph node metastasis $\quad(p=0.0095)$, which was higher $(14.68 \pm 8.23)$ in the patients not having lymph node metastasis as compared to patients showing lymph node metastasis $(9.73 \pm 5.75)$. There was no significant correlation between expression levels of IGF-II, VEGF and IMD with any of the other clinicopathological features, including age, menopausal status or tumor stage. 


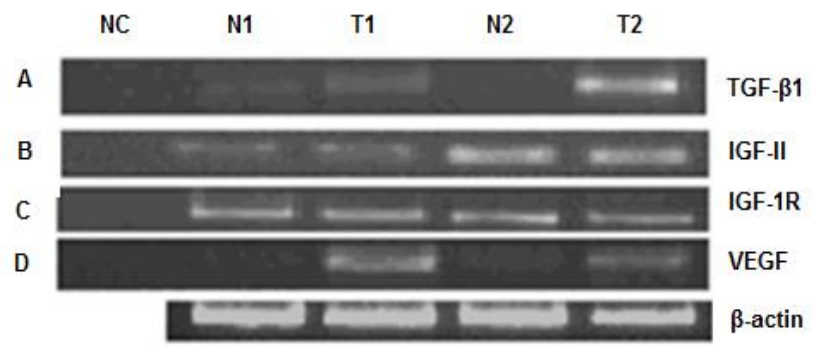

Figure 1A: Agarose gel electrophoresis showing RT-PCR product (A) 2.5\% agarose gel showing $161 \mathrm{bp}$ band of TGF- $\beta 1$ gene, (B) $2.0 \%$ agarose gel showing product of $258 \mathrm{bp}$ of IGF-II gene, (C) $1.5 \%$ agarose gel showing 883 bp band of IGF-1R gene, (D) $2.0 \%$ agarose gel showing $341 \mathrm{bp}$ of VEGF gene in paired normal and tumor breast tissues( NC, negative control; N, normal tissue; T, tumor tissue).

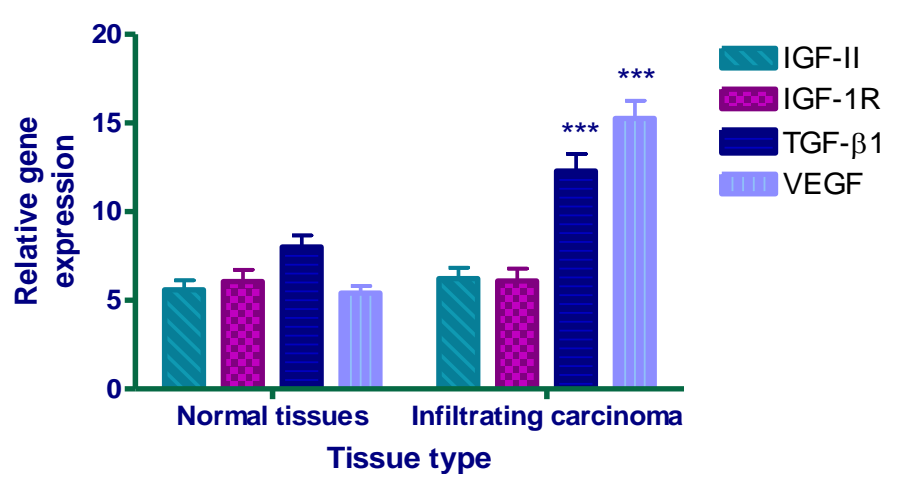

Figure 1B: Distribution of relative mRNA expression of IGF-II, IGF-1R, TGF- $\beta 1$ and VEGF genes in normal tissues $(n=60)$ and infiltrating breast carcinoma $(n=60)$, normalized to the content of $\beta$-actin in each sample (e.g. expressed as the $\%$ of $\beta$-actin gene), $* * *$ signifies $\mathrm{p}<0.001$.

\section{Correlation of TGF- $\beta 1, I G F-I I, I G F-1 R, m R N A$ expression with levels of VEGF gene expression and IMD in Infiltrating Breast Carcinoma}

Table 3 shows the correlation matrix (Pearson's correlation coefficients) depicting the association between mRNA expression of TGF$\beta 1$, IGF-II, IGF-1R, VEGF genes and IMD scores in infiltrating breast carcinoma samples. A positive correlation was observed between the TGF- $\beta 1$ gene expression with VEGF gene expression $(\mathrm{r}=0.112, \mathrm{p}=0.396)$ and IMD scores

Am. J. Biomed. Sci. 2009, 1(2), 157-165; doi: 10.5099/aj090200157 $(\mathrm{r}=0.040, \mathrm{p}=0.764)$. Correlation analysis of intratumoral expression of various genes viz. IGFII vs IGF-1R, IGF-1R vs VEGF genes, VEGF vs IMD scores revealed a positive correlation, though it was not statistically significant $(\mathrm{p}>0.05$, Table $3)$.

\section{Discussion}

The angiogenesis depends on the production of several growth factors and angiogenic factors such as TGF- $\beta 1$ and VEGF, by tumor cells and normal cells [25]. TGF- $\beta 1$ has known angiogenic effect in breast cancer [13-14] but, acts as an indirect angiogenic agent as shown by our previously published study [15]. Our results were in concordance with the findings of Cardillo et al [26], which showed that the expression of TGF- $\beta 1$ gene was significantly higher in infiltrating tumor tissue than normal tissue. These results might be related to the ability of TGF- $\beta 1$ to down regulate members of the metalloprotein family such as tissue Inhibitors of metalloproteinases 1 (TIMP1) and 2 and to upregulate the transcription of genes like collagen and fibronectin.

TGF- $\beta 1$ secreted by tumor cells or by macrophages or fibroblasts from tumor stroma also can induce angiogenesis [27]. In our study, a positive correlation was observed between intratumoral TGF- $\beta 1$ and VEGF expression $(\mathrm{r}=0.112, \mathrm{p}=0.396)$ and support the findings of Breier et al [28] and Donovan et al [29], which suggested that TGF- $\beta 1$ activated at the tumor/stroma border induces VEGF expression in the tumor periphery. In a study by Kesari et al [30], an inverse correlation was observed between TGF- $\beta 1$ expression and microvessel density $(\mathrm{r}=$ 0.311 ) and they suggested that TGF- $\beta 1$ may inhibit proliferation of vascular endothelium. On the contrary, in the current study, there was a positive correlation between the intratumoral TGF- $\beta 1$ and IMD $(r=0.040, p=0.764)$ and the findings conclude that there is a relationship of TGF- $\beta 1$ with VEGF and IMD in breast carcinoma patients.

Studies to date have been inconsistent with regard to expression of IGF-system components in breast tumor and normal breast tissue. In our study, the levels of IGF-II mRNA were higher in 
tumor bed as compared to normal tissues. Our data is in accordance with the findings of Pekonen et al [31], which suggest that the presence of high level of IGF-II transcripts in breast tumor tissue may create an environment which stimulate cell proliferation and inhibit apoptosis with increased potential for tumor growth promoting signal transduction. Our observation with respect to differences between normal and tumor tissues may in part be due to differences in prominent cell types in these tissues.

Table 2. Analyses of TGF-ß1, IGF-II, IGF-1R, VEGF expression and microvessel density (MVD) in different tumor lesion types, their relationship with age, lymph node metastasis, tumor stage, histological tumor grade and menopausal status in infiltrating breast carcinoma.

\begin{tabular}{|c|c|c|c|c|c|c|c|c|c|c|}
\hline Parameter & $\begin{array}{l}\text { Relative } \\
T G F-\beta 1 \\
\text { mRNA } \\
\text { expression }\end{array}$ & pvalue & $\begin{array}{l}\text { Relative } \\
I G F-I I \\
\text { mRNA } \\
\text { expression }\end{array}$ & pvalue & $\begin{array}{l}\text { Relative IGF-IR } \\
\text { mRNA } \\
\text { expression }\end{array}$ & pvalue & $\begin{array}{l}\text { Relative } \\
\text { VEGF } \\
\text { mRNA } \\
\text { expression }\end{array}$ & pvalue & MVD Scores & pvalue \\
\hline Tumor Type & & 0.0004 & & NS & & NS & & $<0.0001$ & & \\
\hline Normal tissue $(\mathrm{n}=60)$ & $8.00 \pm 5.13$ & & $5.60 \pm 4.01$ & & $6.05 \pm 5.29$ & & $5.40 \pm 3.22$ & & & \\
\hline$\leq 48$ & $11.69 \pm 5.68$ & & $6.43 \pm 4.68$ & & $7.63 \pm 1.35$ & & $13.40 \pm 5.97$ & & $135.65 \pm 46.38$ & \\
\hline$>48$ & $12.71 \pm 1.65$ & & $5.94 \pm 3.87$ & & $4.56 \pm 4.56$ & & $16.46 \pm 7.98$ & & $156.90 \pm 92.43$ & \\
\hline Lymph node metastasis & & 0.0095 & & NS & & NS & & NS & & NS \\
\hline Node negative (N-) & $14.68 \pm 8.23$ & & $6.46 \pm 4.77$ & & $4.98 \pm 4.08$ & & $16.10 \pm 7.86$ & & $147.87 \pm 71.22$ & \\
\hline IIIA and IIIB & $11.41 \pm 7.28$ & & $7.67 \pm 5.82$ & & $8.43 \pm 7.53$ & & $13.37 \pm 6.43$ & & $144.42 \pm 33.53$ & \\
\hline $\begin{array}{l}\text { Infiltrating ductal tumor } \\
\text { grade }\end{array}$ & & NS & & NS & & 0.0483 & & NS & & NS \\
\hline Grade I & $9.06 \pm 6.30$ & & $7.07 \pm 7.88$ & & $6.06 \pm 6.34$ & & $16.99 \pm 9.58$ & & $104.50 \pm 28.50$ & \\
\hline Grade II & $12.58 \pm 7.24$ & & $5.98 \pm 4.10$ & & $5.23 \pm 4.72$ & & $14.80 \pm 7.53$ & & $143.54 \pm 70.30$ & \\
\hline Grade III & $11.82 \pm 8.03$ & & $6.81 \pm 4.97$ & & $9.86 \pm 6.48$ & & $14.16 \pm 7.39$ & & $167.63 \pm 95.88$ & \\
\hline Menopausalstatus & & NS & & NS & & NS & & NS & & NS \\
\hline Postmenopausal & $14.35 \pm 7.44$ & & $6.94 \pm 5.72$ & & $6.90 \pm 5.85$ & & $16.98 \pm 7.48$ & & $137.44 \pm 50.68$ & \\
\hline Premenopausal & $9.60 \pm 6.82$ & & $5.30 \pm 2.77$ & & $5.04 \pm 4.71$ & & $13.00 \pm 7.59$ & & $155.30 \pm 91.82$ & \\
\hline
\end{tabular}

Values tabulated are means \pm standard errors of mean. NS: non-significant.

Table 3. Correlation matrix (Pearson's correlation coefficients) of the association between mRNA expression of TGF- $\beta 1$, IGF-II, IGF-1R, VEGF genes and IMD scores in infiltrating breast carcinoma samples

\begin{tabular}{|c|c|c|c|}
\hline & IGF-1R & VEGF & IMD \\
\hline TGF- $\beta 1$ & & $0.112(\mathrm{p}=0.396)$ & $0.040(\mathrm{p}=0.764)$ \\
\hline IGF-II & $0.183(\mathrm{p}=0.161)$ & & $-0.208(\mathrm{p}=0.110)$ \\
\hline IGF-1R & & $0.051(\mathrm{p}=0.698)$ & \\
\hline VEGF & & & $0.065(\mathrm{p}=0.621)$ \\
\hline
\end{tabular}


IGF-II can bind to both the type 1 and 2 IGF receptors. The type 2 receptor does not appear to mediate a mitogenic response and it is felt that the mitogenic response caused by IGF-II is mediated mainly through type 1 receptor. A positive correlation in the expression levels $(\mathrm{r}=0.183$, $\mathrm{p}=0.161$ ) of IGF-II and IGF-1R suggest that both are co-regulated. Lee et al [16] provided the evidence that IGF-II directly promotes angiogenesis by stimulating migration and morphological differentiation of endothelial cells, and suggested that IGF-II may play a role in the progression of tumor growth by promoting the deleterious neovascularization. But, a negative correlation between IGF-II expression and IMD score $(r=-0.208, p=0.110)$ in our study indicates that IGF-II may help tumorigenesis, not by the expansion of endothelial cells [8], but probably because of its mitogenic properties, exerting its effects by increased proliferation and reduced apoptosis.

In our study, we observed marginally higher levels of IGF-1R in breast tumors than normal breast tissues, which is found to be significantly raised in high grade lesions as compared to low grade lesions $(p=0.0483)$ suggesting that the overexpression of IGF-1R is associated with aggressive behavior of the breast tumor. However, there was no correlation between IGF-1R gene expression and menopausal status, tumor stage, or lymph node metastasis. One possible explanation of this could be the small sample size in the present study. We observed a positive correlation between IGF-1R values and VEGF expression $(\mathrm{r}=0.051, \mathrm{p}=0.698)$ in infiltrating breast carcinoma indicating that IGF-1R might have a potential role in promoting angiogenesis by the induction of VEGF expression in tumor tissues as has been reported by Kucab and Dunn [17], who considered the potential role of IGF-1R in regulating breast cancer metastases by facilitating angiogenesis and lymphangiogenesis through the induction of VEGF.

In conclusion, the results of the present study indicate that paracrine activation of IGF-1R by IGF-II and overexpression of TGF- $\beta 1$ by the tumor, may result in an increased mitogenic action which contributes to the progression and angiogenesis of the tumor. TGF- $\beta 1$ seems to affect tumor angiogenesis and play an important role in breast tumor progression. The determination of tissue TGF- $\beta 1$ levels may be informative in considering therapy for these patients.

\section{Acknowledgements}

The work was supported by the Institute research funding. We also acknowledge the support from Indian Council of Medical Research (ICMR), New Delhi, in form of Ph.D. fellowship to Sachin Gupta. We are thankful to Mrs. Alka Verma for her technical support in immunohistochemistry. The authors are thankful to Mrs Chhavi Gupta for her timely help in editing and revising the manuscript.

\section{References}

1. Knabbe, C.; Lippmann, M.E.; Wakefield, L.M, et al. Evidence that transforming growth factor beta is a hormonally regulated negative growth factor in human breast cancer cells. Cell, 1987, 48, 417-428.

2. Arrick, B.A.; Lopez, A.R.; Elfman, F.; et al. Altered metabolic and adhesive properties and increased tumorigenesis associated with increased expression of transforming growth factor beta $1 . J$ Cell Biol, 1992, 118, 715-726

3. Mourskaia, A.A.; Dong, Z.Ng S.; Banville, M.; Zwaagstra, J.C.; O'Connor-McCourt, M.D.; Siegel, P.M. Transforming growth factor-betal is the predominant isoform required for breast cancer cell outgrowth in bone. Oncogene, 2008, 1-11.

4. Marrogi, A.J.; Munshi, A.; Merogi, A.J.; Ohadike, Y.; Habashi, A.E.; Marrogi, O.L.; and Freeman, S.M. Study of tumor infilterating lymphocytes and transforming growth factor beta as prognostic factors in breast carcinoma. Int J Cancer, 1997, 74, 492-501.

5. Jones, R.A.; Moorehead, R.A. The Impact of Transgenic IGF-IR Overexpressionon Mammary Development and Tumorigenesis. J Mammary Gland Biol Neoplasia, 2008, 13, 407-413.

6. Yee, D. The insulin like growth factor system as a target in breast cancer. Breast Cancer Res Treat, 1994, 32, 85-95.

7. Clemmons, D.R.; Camacho-Hubner, B.; Coronado, E.; et al, Insulin like growth factor binding protein secretion by breast carcinoma cell lines. Correlation with estrogen receptor status. Endocrinogy, 1989, 127, 2679-2686

(C) 2009 by NWPII. All rights reserved. 
8. Moschos, S.J.; Mantzoros, C.S. The role of the IGF system in cancer: from basic to clinical studies and clinical applications. Oncology, 2002, 63, 317-332.

9. Ferrara, N.; Heinsohn, H.; Walder, C.E.; Bunting, S.; Thomas, G.R. The regulation of blood-vessel growth by vascular endothelial growth factor. Ann N Y Acad Sci, 1995, 752, 246-256.

10. Barbareschi, M.; Gasparini, G.; Morelli, L.; et al. Novel methods for the determination of the angiogenic activity of human tumors. Breast Cancer Res Treat, 1995, 36, 181-192.

11. Castello, P.; McCann, A.; Carney, D.N.; Derven, P.A. Prognostic significance of microvessel density in lymph node negative breast carcinoma. Hum Pathol, 1995, 26, 1181-1184.

12. Pertovaara, L.; Kaipainen, A.; Mustonen, T.; Orpana, A.; Ferrara, N.; Saksela, O.; et al. Vascular endothelial growth factor is induced in response to transforming growth factor- $\beta$ in fibroblastic and epithelial cells. J Biol Chem, 1994, 269(9), 6271-6274.

13. Ueki, N.; Nakazato, M.; Ohkawa, T.; et al. Excessive production of TGF- $\beta 1$ can play an important role in the development of tumorigenesis by its action for angiogenesis: validity of neutralizing antibodies to block tumor growth. Biochim Biophys Acta, 1992, 1137, 189-196.

14.Fajardo, L.F.; Prionas, S.D.; Kwan, H.H.; Kowalski, J.; Allison, A.C. Transforming growth factor $\beta 1$ induces angiogenesis in vivo with a threshold pattern. Lab Invest, 1996, 74, 600-608.

15. Gupta, S.; Joshi, K.; Wig, J.D.; Arora, S.K. Intratumoral FOXP3 expression in infiltrating breast carcinoma: Its association with clinicopathologic parameters and angiogenesis. Acta Oncol, 2007, 46(6), 792797.

16.Lee, O.H.; Bae, S.K.; Bae, M.H.; Lee, Y.M.; Moon, E.J.; Cha, H.J.; Kwon, Y.G.; Kim, K.W. Identification of angiogenic properties of insulin-like growth factor II in in vitro angiogenesis models. $\mathrm{Br} J$ Cancer, 2000, 82(2), 385-391.
17. Kucab, J.E.; Dunn, S.E. Role of IGF-1R in mediating breast cancer invasion and metastasis. Breast Dis, 2003, 17, 41-47.

18. Kinne, D.W. Staging and follow-up of breast cancer patients. Cancer, 1991, 67, 1198.

19.Elston, C.W.; Ellis, I.O. Pathological prognostic factors in breast cancer. The value of histological grades in breast cancer. Experience from a large study with long term follow-up. Histopathology, 1991, 19, 403-410.

20. Sambrook, J.; Russell, D.W. Molecular cloning- A Laboratory Manual. $3^{\text {rd }}$ Edition, 2001.

21.Suga, K.; Imai, K.; Egushi, H.; Hayashi, S.; Higashi, Y.; Nakachi, K. Molecular significance of excess body weight in postmenopausal breast cancer patients in relation to expression of insulin-like growth factor 1 receptor and insulin-like growth factor II genes. Jpn J Cancer Res, 2001, 92, 127-134.

22. Shaw, L.C.; Afzal, A.; Lewin, A.S.; Timmers, A.M.; Spoerri, P.E.; Grant, M.B. Decreased expression of the insulin-like growth factor 1 receptor by ribozyme cleavage. Invest. Opthal Visual Sci, 2003, 44(9), 4105-4113.

23. Awad, B.E.; Kneft, B.; Wolber, E.M.; Burgel, T.H.; Metzen, E.; Fandrey, J.; Jelkmann, W. Hypoxia and interleukin-1 $\beta$ stimulate vascular endothelial growth factor production in human proximal tubular cells. Kidney International, 2000, 58, 43-50.

24. Weidner, N.; Semple, J.P.; Welch, W.R.; Folkman, J. Tumor angiogenesis and metastasis- correlation in invasive breast carcinoma. N Engl J Med, 1991, 324, 1-8.

25. Nelson, N.J. Angiogenesis research is on fast forward [news]. J Natl cancer Inst, 1999, 91(10), 820-822.

26. Cardillo, M.R.; Yap, E.; Castagna, G. Molecular genetic analysis of TGF beta1 in breast cancer. J Exp Clin Cancer Res, 1997, 16(1), 57-63.

27. Roberts, A.B.; Sporn, M.B. Transforming growth factor- $\beta$ s rapid induction of fibrosis and angiogenesis in vivo and stimulation of collagen formation in vitro. Proc Natl Acad Sci USA, 1986, 83, 4167-4171.

28. Breier, G.; Blum, S.; Peli, J.; Groot, M.; et al. Transforming growth factor- $\beta$ and Ras

(C) 2009 by NWPII. All rights reserved. 
regulates the VEGF/VEGF-receptor system during tumor angiogenesis. Int J cancer, 2002, 97, 142-148.

29. Donovan, D.; Harmey, J.H.; Toomey, D.; Osborne, D.H.; Redmond, H.P.; BouchierHayes, D.J. TGF beta-1 regulation of VEGF production by breast cancer cells. Ann of Surg Oncol, 1997, 4, 621-627.

30. Kesari, A.L.; Chellam, V.G.; Mathew, B.S.; Nair, M.K.; Pillai, M.R. Transforming Growth
Factor Beta Related to Extent of Tumor Angiogenesis but Not Apoptosis or Proliferation in Breast Carcinoma. Breast Cancer, 1999, 6(1), 29-36.

31.Pekonen, F.; Partanen, S.; Makinen, T.; Rutanen, E.M. Receptors for epidermal growth factor and insulin-like growth factor I and their relation to steroid receptors in human breast cancer. Cancer Res, 1988, 48, 1343-1347. 